\title{
Характеризация динамических решеток инверсии населенности в иттербиевом волокне
}

\author{
P.В. Дробышев ${ }^{*}$, И.А. Лобач, С.И. Каблуков \\ Институт автоматики и электрометрии СО РАН \\ *E-mail: r.drobyshev@mail.ru
}

DOI: 10.31868/RFL2020.57-58

Усиление и обратная связь определяют характеристики генерации в лазерных системах. Необычные лазерные характеристики наблюдаются, когда обратная связь в лазере в виде динамических решеток показателя преломления и/или усиления формируется генерируемым излучением. В частности, было показано, что динамическая распределенная связь в волоконных лазерах приводит к регулярной динамике спектра генерации - самосканированию частоты [1]. Было установлено, что решетка инверсии состоит из двух компонент: амплитудной и фазовой [1]. Амплитудная решетка (решетка усиления) обусловлена пространственным выжиганием дыр и способствует затуханию моды, записавшей решетку, а фазовая решетка (решетка показателя преломления) выводит в генерацию соседнюю моду, которая потом создает свою решетку инверсии. Таким образом спектр отражения динамической решетки меняется со временем, и положение его пика определяет частоту генерации, что приводит к перестройке частоты лазера. Динамические решетки уже изучались ранее: были сделаны оценки их коэффициента отражения как при помощи моделирования [2], так и экспериментально [3]. Однако формирование динамических структур непосредственно в схемах сканирующего лазера не всегда удобно, поскольку накладывает определённые требования к конфигурации резонатора. В частности, необходимо подбирать коэффициенты отражения зеркал и длины активных и пассивных волокон. По этой причине, для изучения свойств динамических решеток удобнее формировать их с помощью внешнего источника излучения в схеме интерферометра.
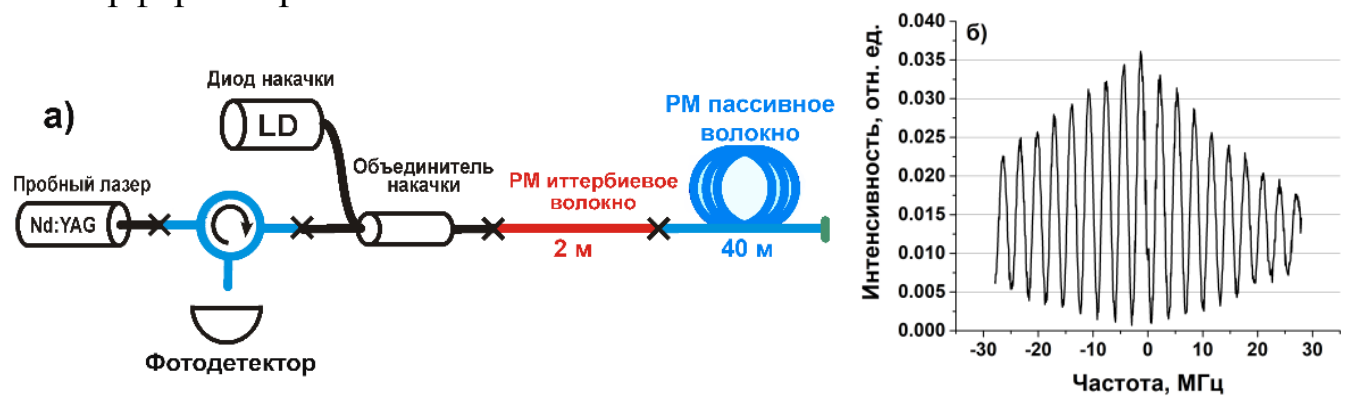

Рис. 1 a) Схема экспериментальной установки, б) спектр отраженного сигнала

Схема для изучения динамических структур инверсии населенности в активном волокне представлена на Рис.1а. Решетка инверсии в данном случае возникает в активной среде благодаря влиянию стоячей волны, появившейся вследствие отражения излучения одночастотного $\mathrm{Nd}: \mathrm{YAG}$ лазера от торца сколотого под прямым углом пассивного волокна. Инверсная населённость в активном волокне (Nufern PM-YDF-5/130-VIII) длиной около 2 м достигается за счет ввода многомодового излучения с длиной волны 970 нм. После формирования решетки в течение длительного времени происходит ее считывание, которое осуществляется с помощью того же самого источника, но уже при перестройке частоты генерации. Это позволяет прописать часть спектра 
решетки шириной около $~ 50$ МГц [3]. Стоит отметить, что длительность записи динамических решеток ( 4 мс) превосходит их время жизни, поэтому можно утверждать, что в момент тестирования решетки в среде существует только одна динамическая решетка. В то же время сам процесс тестирования должен быть достаточно быстрым по времени ( 300 мкс), чтобы не произошло искажения спектра отражения из-за её релаксации. Характерный спектр сигнала, регистрируемого фотодетектором, представлен на Рис.1б. Регистрируемый сигнал является результатом интерференции двух волн, отраженных от динамической решетки и от выходного зеркала (торца волокна). Коэффициенты отражения скола и решетки сравнимы друг с другом, поэтому результат интерференции выглядит в виде гармонических осцилляций. Период интерференции определяется разностью оптических путей между двух отражателей. Интерференционная картина в форме огибающей несет информацию об амплитуде и ширине спектра отражения динамической решетки, а в фазе высокочастотных осцилляций - об относительном влиянии решеток усиления и показателя преломления. Для удобства извлечения параметров огибающей и фазы осцилляций из сигнала интерференции в схему был добавлен кусок пассивного волокна длиной 40 метров, позволивший увеличить частоту осцилляций в интерференционной картине. Результат обработки серии измерений представлен на Рис. 2. На рисунке 2a представлен характерный спектр динамической решетки при среднем уровне мощности накачки. На рисунке 26 показана зависимость коэффициента отражения динамической решетки и фазы высокочастотных осцилляций интерференционной картины от мощности накачки.
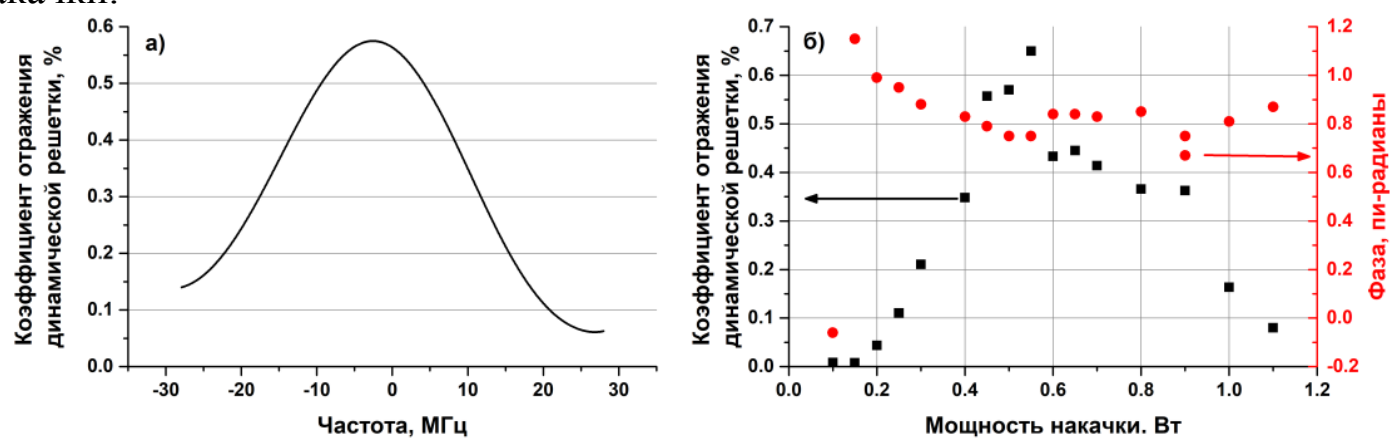

Рис. 2. а) Характерный спектр динамической решетки и б) амплитуда и фаза динамической решетки при разных мощностях накачки активной среды.

Главным результатом является то, что фаза почти не меняется, за исключение скачка на мощности $0.15 \mathrm{BT}$, следовательно, отношение фазовой и амплитудной решеток остается постоянным. Скачок фазы обусловлен переходом от инверсной решетки поглощения к решетке усиления. Измерение модуляции показателя преломления также показало эквивалентность подходов, а величина модуляции соответствует результатам измерений этой величины в динамической решетке самосканирующего лазера, где она составила $\delta \mathrm{n} \sim 3 \cdot 10^{-8}[3]$.

Более подробное описание схемы измерения характеристик динамических решеток и полученных результатов будут представлены в докладе.

Работа была выполнена при поддержке РНФ (грант № 18-12-00243).

\section{Литература}

[1] I.A. Lobach, et al., Laser Physics Letters, 11, 045103 (2014)

[2] P. Peterka, et al., IEEE Journal of Selected Topics in Quantum Electronics 24, 3, 902608 (2018)

[3] R.V. Drobyshev, et al., Opt. Express, 27, 21335-21346 (2019) 